\title{
Queen Elizabeth Hall, en Londres INGLATERRA
}

HUBERT BENNETT, arquitecto de la Greater London

Council

$131-53$

\section{simopsis}

Este edificio ha sido construido para la celebración de conciertos y repre. sentaciones musicales. Tiene un auditorio con capacidad para 1.106 asientos, organizados en una sola planta.

Sin embargo, las instalaciones técnicas que le fueron incorporadas, tales como equipos de proyección de películas, auriculares, etc., hacen que dicha sala sea susceptible de servir para múltiples usos.

Tanto su tratamiento formal como su decoración, son de un funcionalismo y una sinceridad expresiva notables.

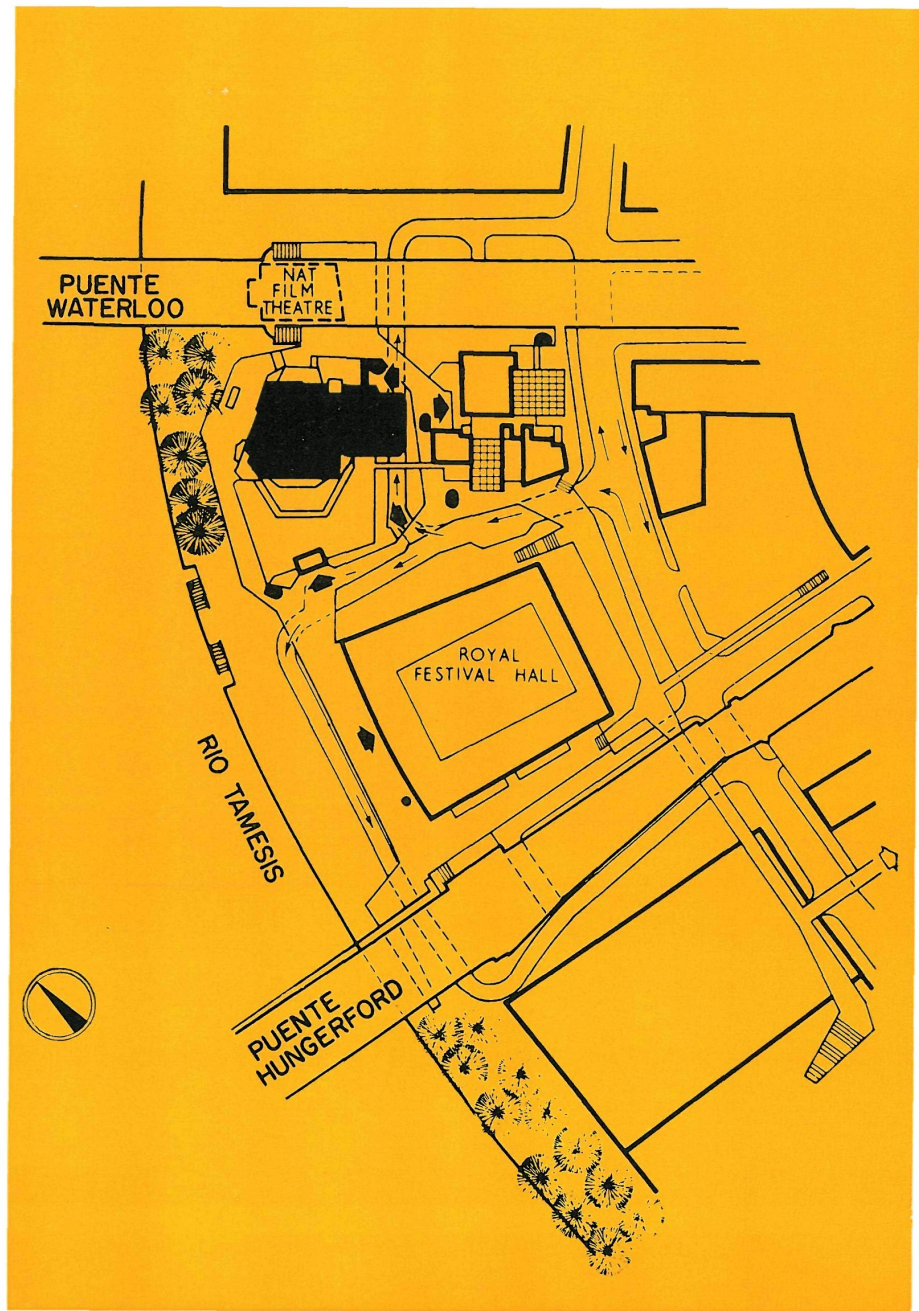

El edificio Queen Elizabeth Hall dispone de un auditorio con una capacidad de 1.106 asientos, organizados en un nivel único. Fue proyectado con gran generosidad de volumen, con objeto de que sirviese adecuadamente para la celebración de conciertos y representaciones musicales.

Las instalaciones adicionales que le fueron incorporadas - una cabina de proyección de películas equipada con los últimos adelantos técnicos; una pantalla de tamaño gigante, a la que va acoplado un sistema de altavoces y que puede ser retirada al extremo del escenario cuando no es necesaria; una instalación de auriculares, etc._- permiten el empleo de la sala para múltiples usos.

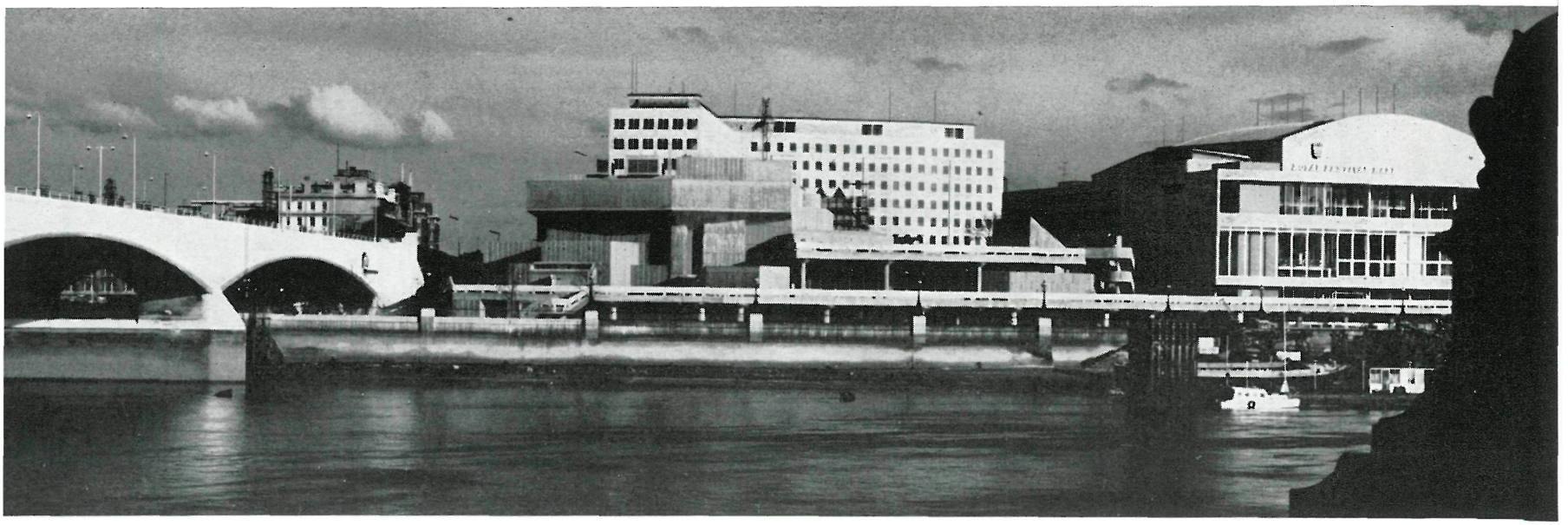



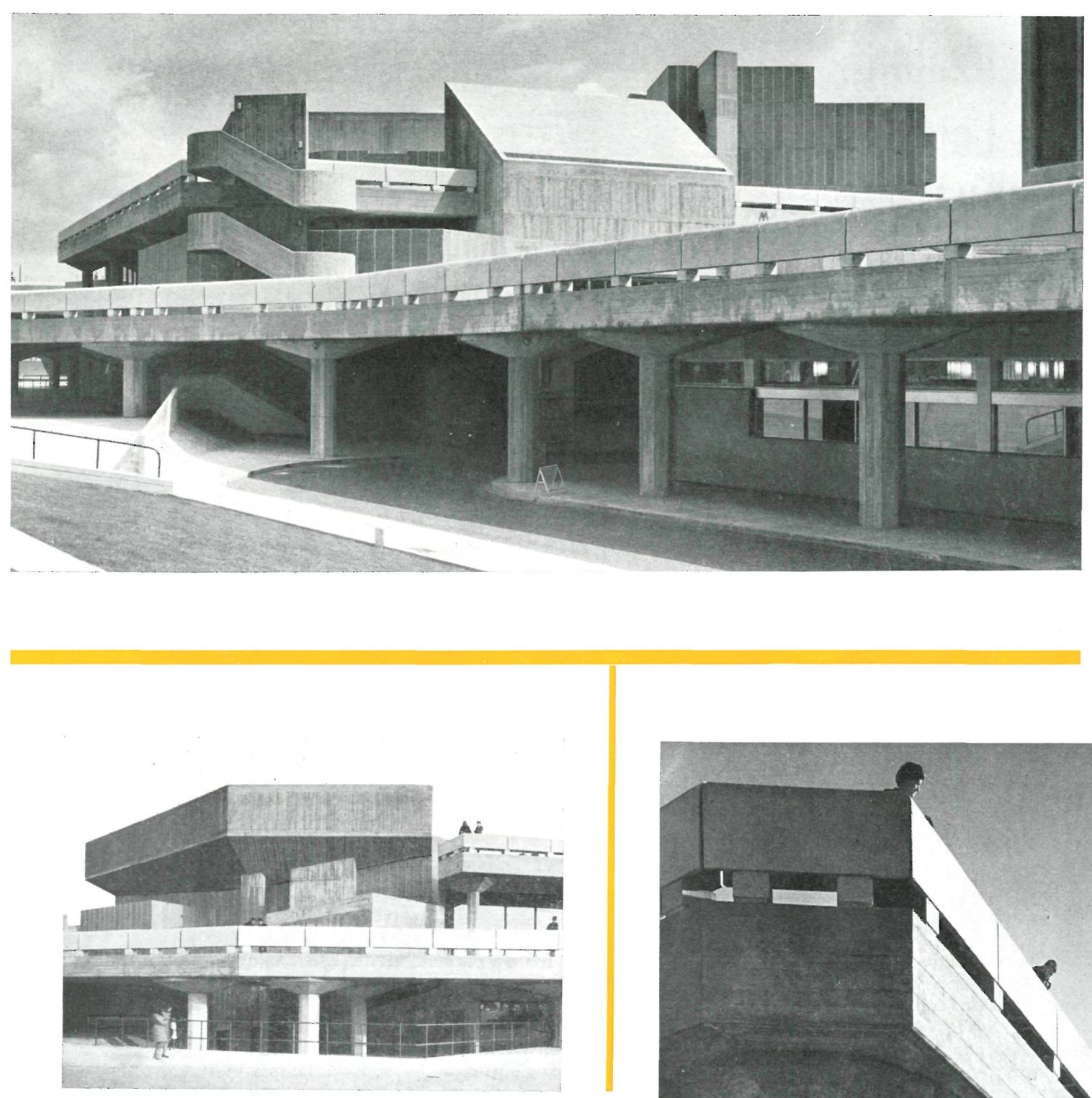

El escenario ha sido diseñado utilizando una serie de secciones que se pueden mover verticalmente mediante mandos eléctricos. Cualquier variación del escenario puede lograrse automáticamente. Las dos secciones más próximas a la zona de audición se pueden bajar si se quiere lograr una localización óptima de la orquesta cuando ésta interprete alguna partitura de música de cámara.

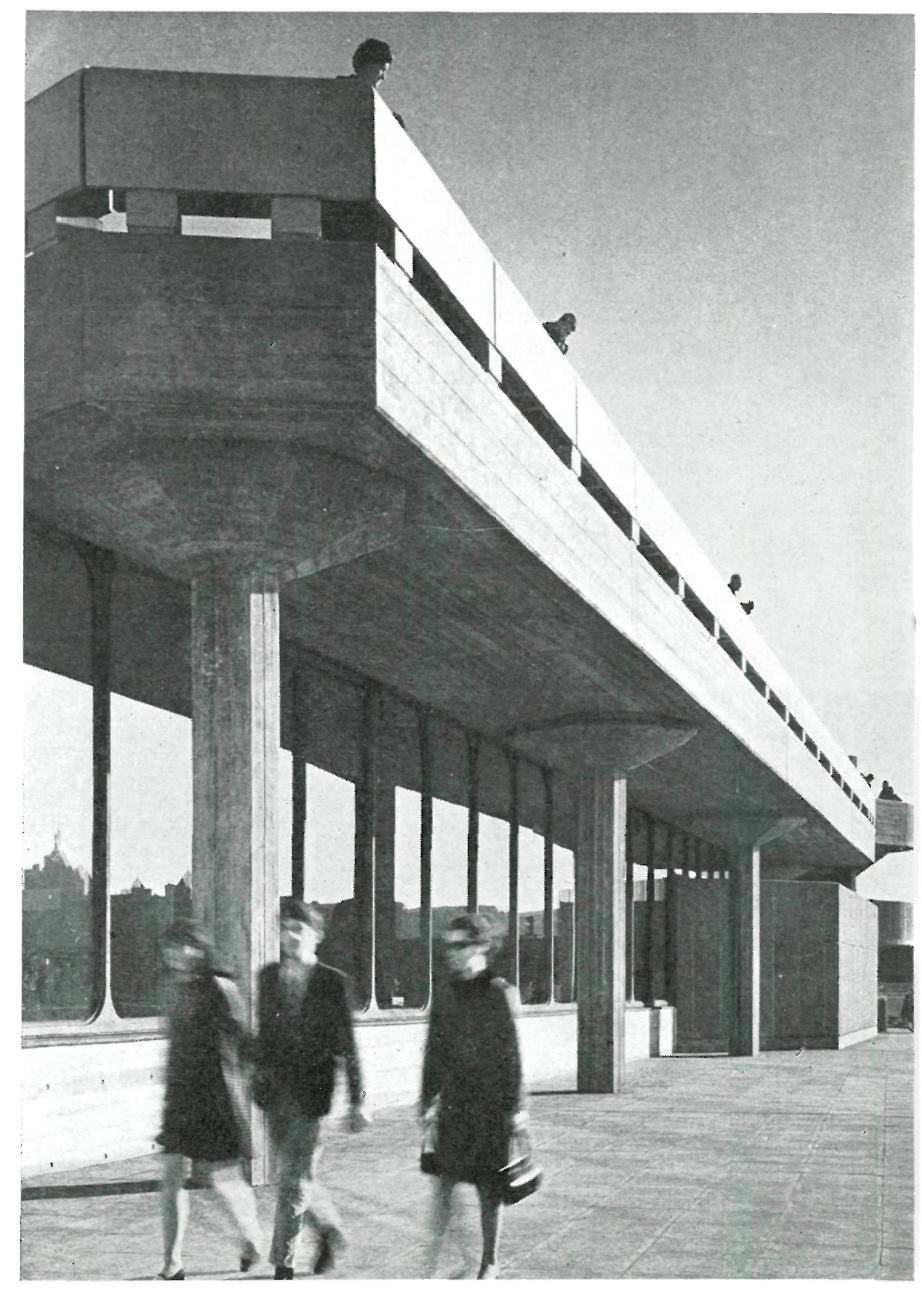


1. Camerino (director).-2. Camerino (solista).-3. Aseos.-4. Espera (director). - 5. Control. -6. Conductos eléctricos.-7. Transformador LEB.-8. Refrigeracion.- - . Refrigeracion.-10. Almacen del bar.-11. Instalaciones.namiento - 16. Artistos - 17. Bar de artistas -18. Espera orquesta - 19. Plataforma auxiliar.-20. Ascensor.-21. Foyer de artistas.-22. Cuarto de basuras. 23. Guarda-portero-24. Organo.

6. Ia EOta de la barreteren

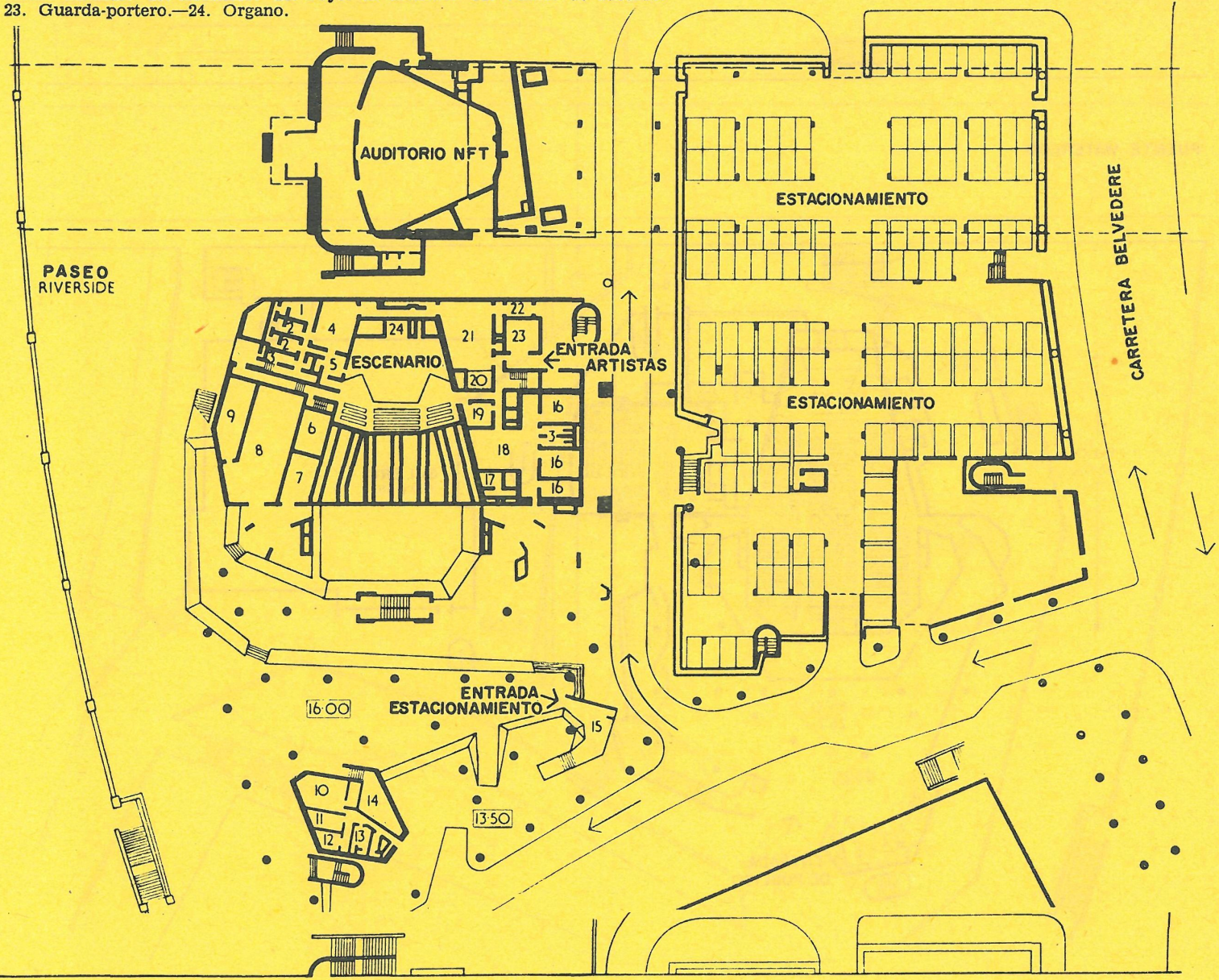

PUENTE

planta

a Uo cota de instalaciones

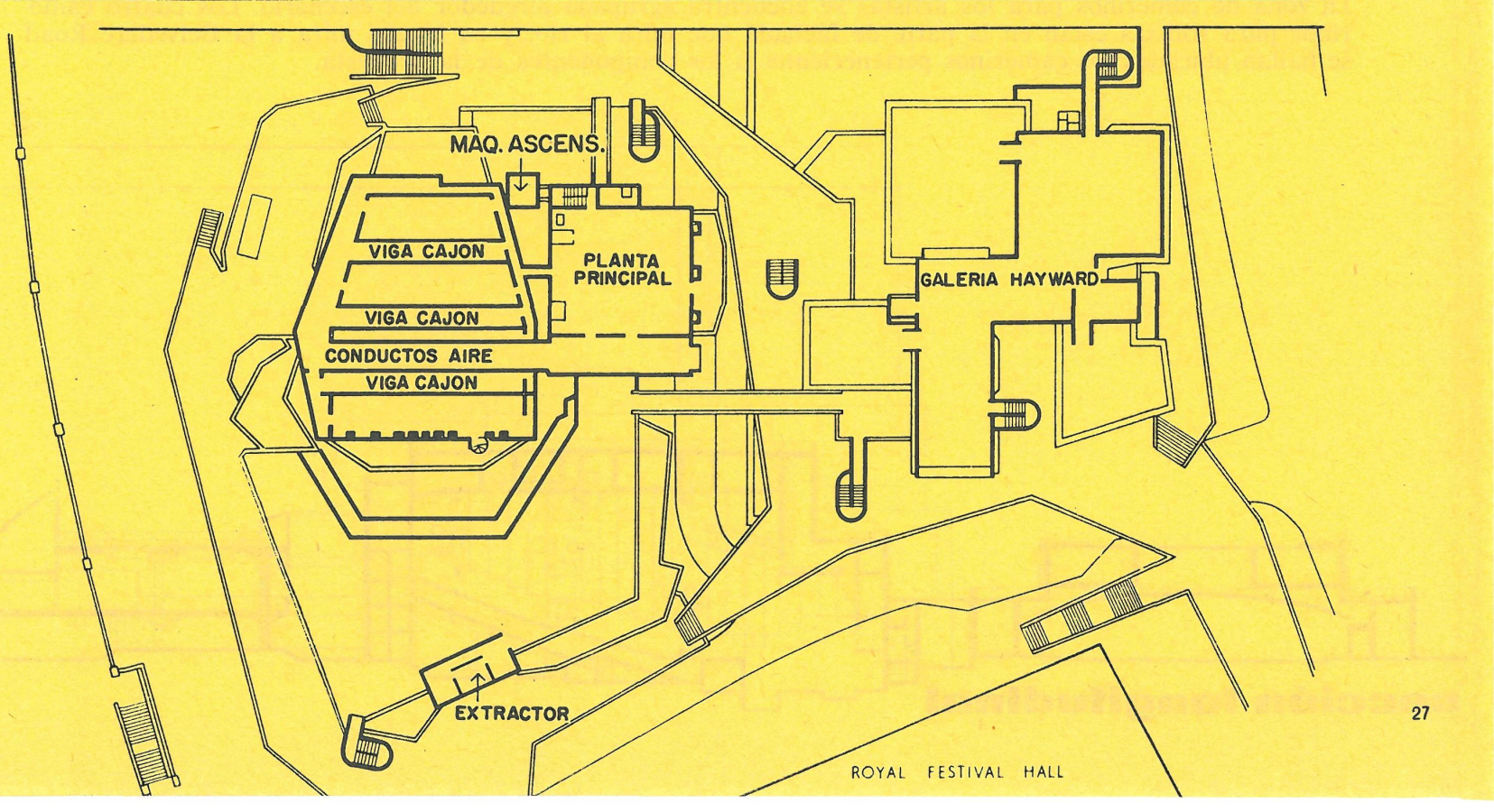


1. Sonido TV. - 2. Cámaras TV. - 3. Teléfonos.-4. Bar.-5. Almacén del bar. -6. Cuarto de preparación. -7. Conmutadores eléctricos.-8. Vestíbulo. Aseos (señoras) -14. Artistas-15. Espera (artistas).-16. Ascensor-17. Cámara TV.

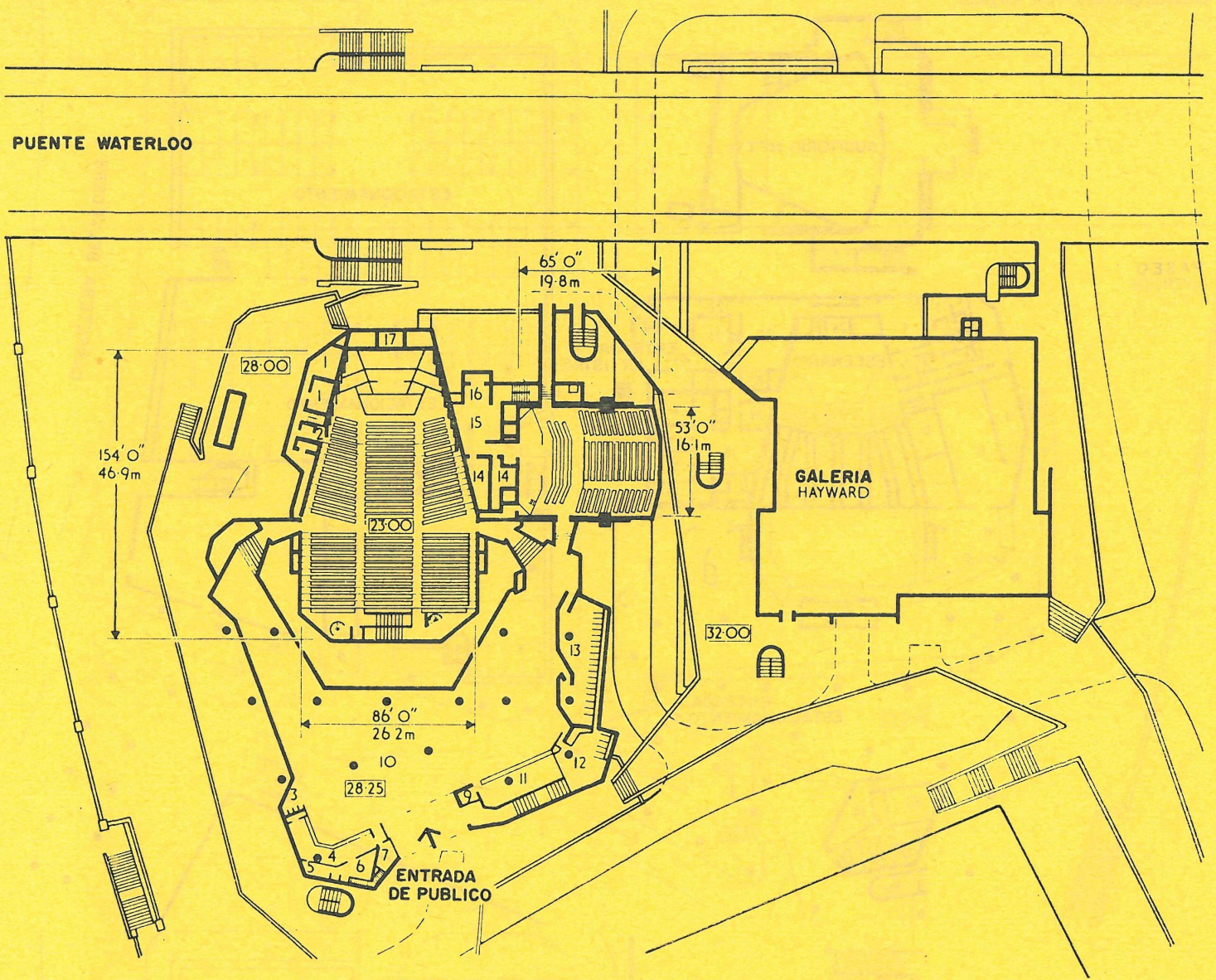

El órgano se halla al fondo del escenario, y los muros y techos que rodean la plataforma del mismo son de hormigón y proporcionan el refuerzo acústico necesario para la correcta audición de música de cámara.

La zona de camerinos para los artistas se encuentra agrupada alrededor del escenario. Los cuatro camerinos para solistas están en la parte de fachada que mira al río, y en la que mira a la Belvedere Road se hallan ubicados los camerinos pertenecientes a los componentes de la orquesta.

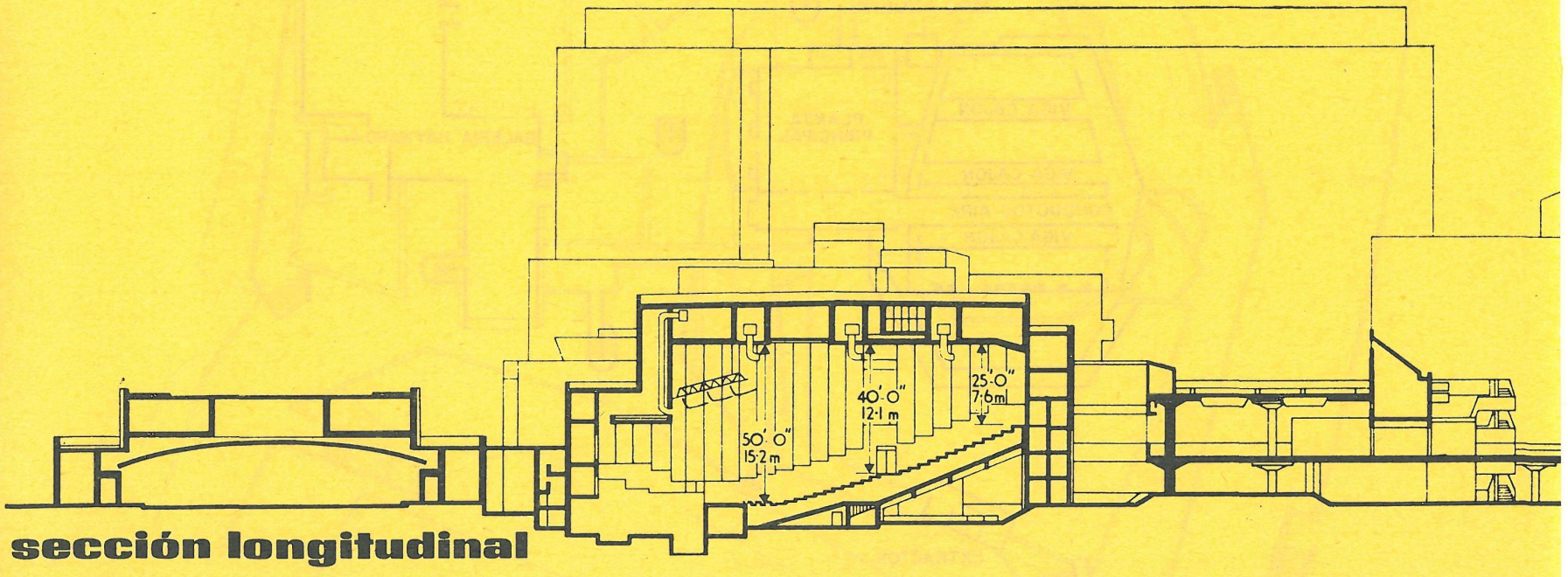




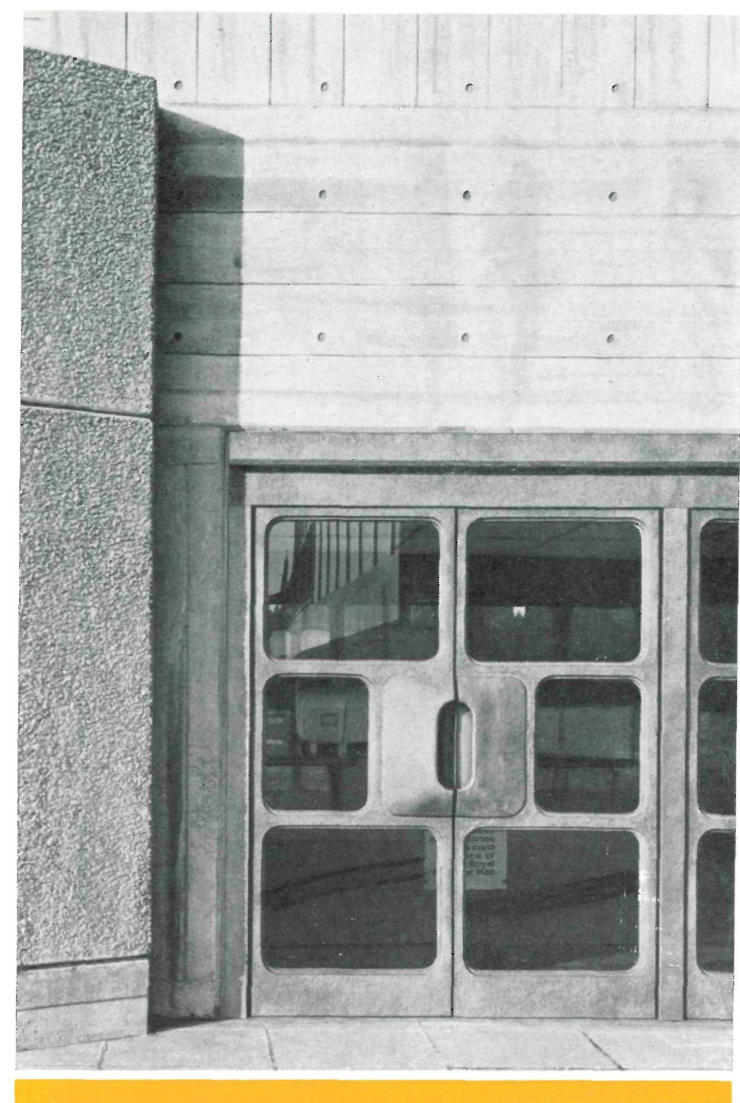

En el auditorio aparecen organizados los 1.106 asientos - ya mencionados- en una sola planta, sin anfiteatros. De este modo fue posible resolver una serie de problemas de acondicionamiento acústico y aprovechar completamente la generosidad del volumen empleado, proyectado para crear óptimas condiciones de reverberación.

Los muros están dotados de dispositivos especiales para absorber los sonidos de baja frecuencia. La madera del suelo, puertas, etc., así como el techo revestido con paneles de yeso, también colaboran como elementos absorbentes.

El modelo de asientos proyectado para la sala permite al espectador graduar la altura de los mismos. asegurando adecuadas líneas de visión libres entre el público y el escenario.

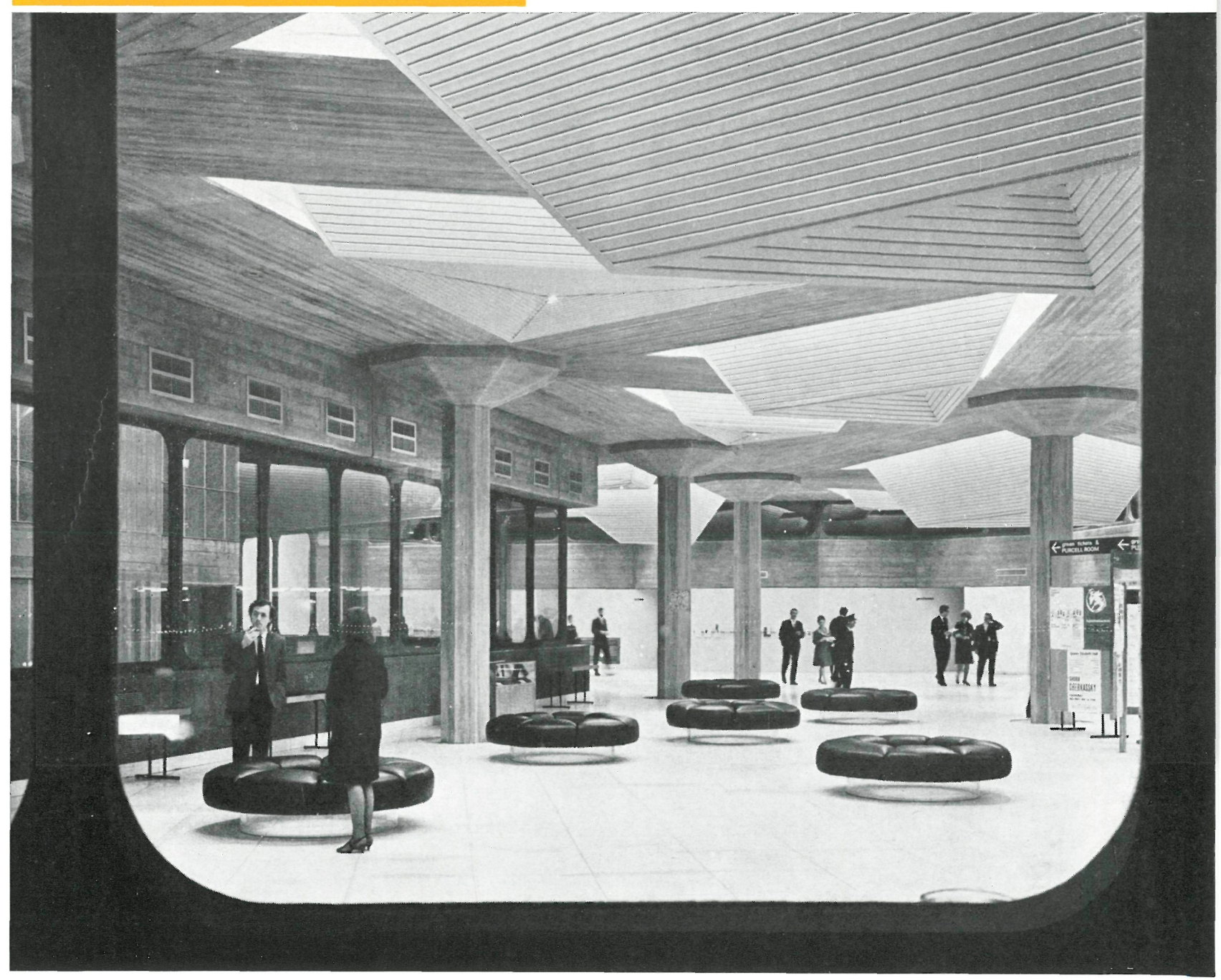




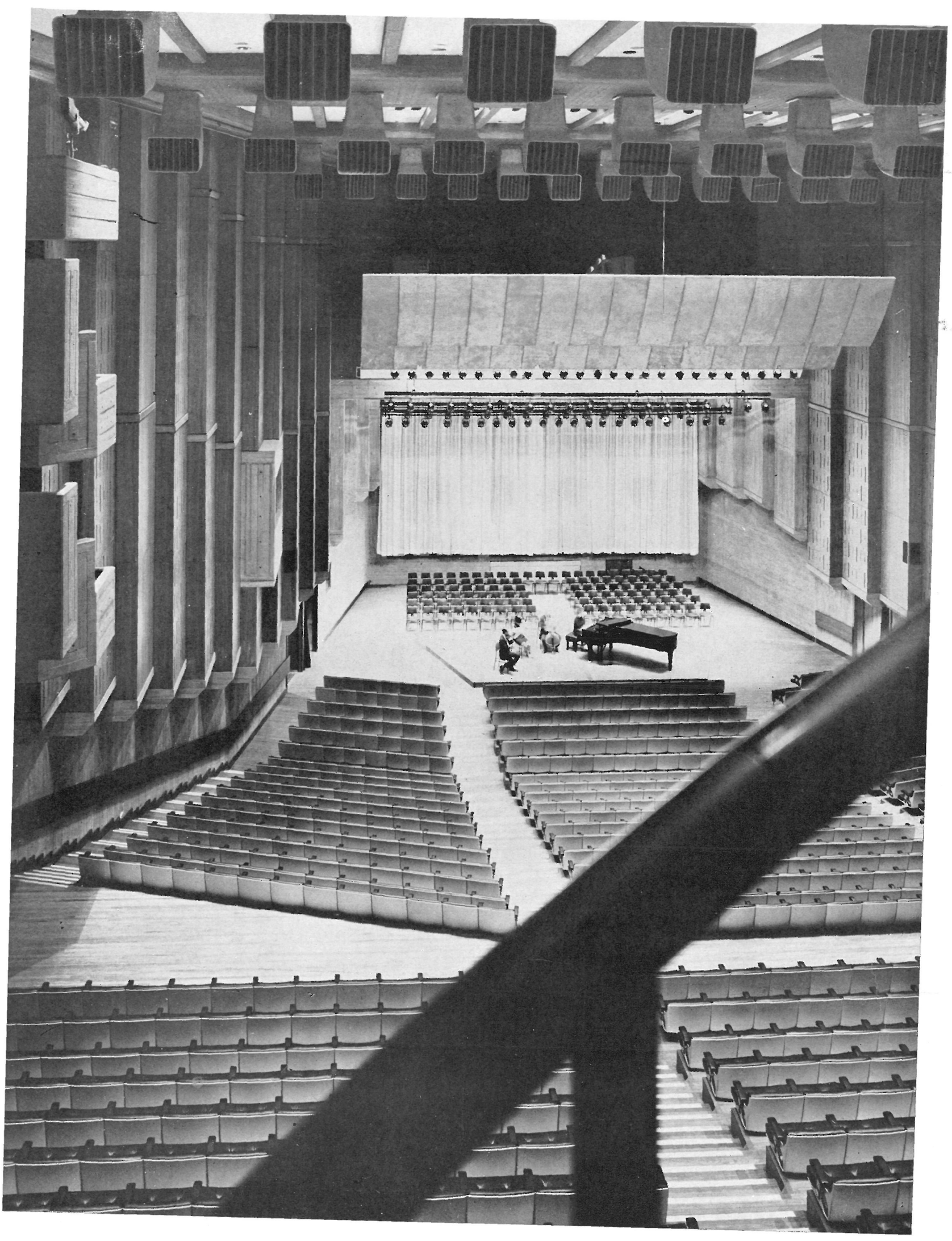


Existen amplios servicios e instalaciones para facilitar las retransmisiones televisivas desde el Queen Elizabeth Hall, emplazados de forma que permitan efectuar las retransmisiones sin molestar al público del auditorio. Además de estos servicios de televisión -hacia el exterior-, existe un circuito cerrado de televisión interior cuyos monitores están situados en los puntos de entrada y en el vestíbulo, con lo cual, cuando ha empezado la función, los espectadores que lleguen con retraso a la representación puedan seguirla a través de las pantallas hasta que se les permita la entrada a la sala.

La sala de recitales anexa, conocida con el nombre de Purcell Room, tiene una capacidad de 372 asientos, con un escenario apropiado para acoger pequeños grupos de cámara. Se han empleado en ella métodos de construcción y de control acústico similares a los utilizados en el auditorio. Está dotada de equipos de proyección móviles, de amplificación de sonido, etc. Además de su mencionada función esencial, está destinada a la presentación de músicos debutantes, y también se puede emplear como sala de conferencias.

En cuanto a la composición estética del conjunto, sus «formas» exteriores expresan las funciones que se desarrollan en el interior. Los elementos dominantes en el edificio son: la estructura del auditorio principal, el vestíbulo, la sala de recitales, y la planta baja.

El auditorio principal se eleva del terreno en el punto extremo del ala transversal, asemejándose en cierto modo a un acantilado rematado por las escaleras de escape situadas en su parte posterior.

La estructura de hormigón se aprecia claramente tanto en el interior como en el exterior.

Fotos: RICHARD EINZIG Y BRECHT-EINZIG LDT.
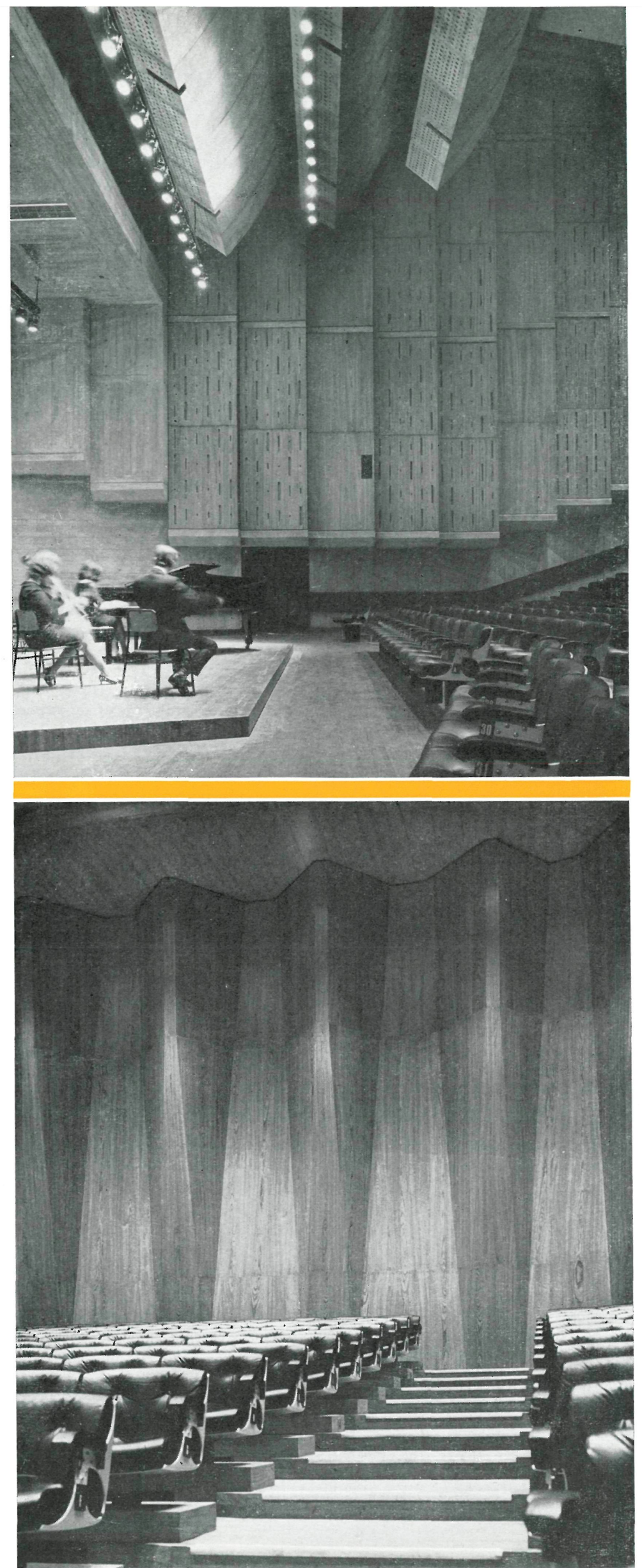
Han sido creadas una serie de terrazas sencillas, pavimentadas con losas cuadradas de granito, cuyas balaustradas albergan las luces para la iluminación de toda esta zona.

El Queen Elizabeth Hall disfruta de una buena iluminación exterior, que resalta la zona superior del auditorio y las terrazas. Los paseos situados a la orilla del río fueron proyectados considerándolos como parte del complejo del South Bank Arts Centre; en ellos la iluminación ha sido efectuada a base de los faroles tradicionales empleados a lo largo del río. Dichos paseos se hallan asimismo flanqueados por una hilera de árboles, cuyo tamaño guarda una escala adecuada en función con los edificios de alrededor.

Desde el otro lado del río, el nuevo complejo se divisa como una expresión original que contrasta con el formalismo del Royal Festival Hall, las oficinas de la Shell y las vigorosas líneas del puente de Waterloo.

Traducido y adaptado por J. M. Rubio.

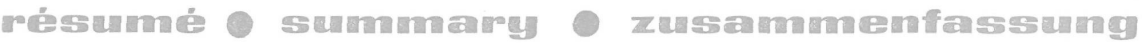

\section{Queen Elizabeth Hall à Lomares - Grande Bretragne}

Hubert Bennett, architecte du Greater London Council

Cet édifice a été construit pour la célébration de concerts et de représentations musicales. Son auditorium, formant un seul niveau, peut contenir 1.106 sièges.

Les installations techniques dont cette salle est dotée - appareil de projection, écouteurs, etc.-, la rendent susceptible de servir à divers usages.

La façon dont elle a été traitée et sa décoration sont fonctionnelles et d'une grande sincérité.

\section{Queen Elizabeth Hall in Lomdon, Great Britraim}

Hubert Bennett, Greater London Council architect

This building has been constructed for the purpose of holding concerts and other musical events. The auditorium has 1106 seats, arranged on a single level.

The auditorium, however, is also fitted with special installations, such as film projectors, earphones and other fittings, which make it suitable for other uses.

Both its formal design and decoration are of an outstandingly expressive functionalism and sincerity.

\section{Queen Elizabeth Hale in London - Gross Britammien}

Hubert Bennett, Architekt des Greater London Council

Dieses Gebäude wurde für Konzerte und sonstige Musikveranstaltungen vorgesehen. Der Zuschauerraum hat eine Kapazität von 1106 Plätzen und verfügt nur über das Parkett.

Die technischen Einrichtungen des Gebäudes sind jedoch so mannigfaltig, z.B. Vorrichtungen zur Filmprojektion, Kopfhöranlage, usw., so dass Veranstaltungen verschiedenster Art hier abgehalten werden können.

Die Bauformen, sowie die Dekoration sind äusserst zweckdienlich und von bemerkenswerter Aufrichtigkeit. 